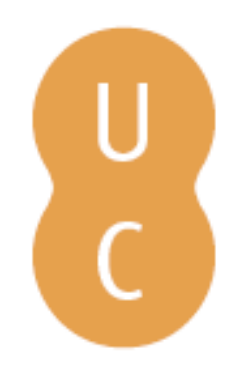

\title{
nombalina
}

\section{A orientação na negociação das transições de carreira ao longo da vida adulta}

\author{
Autor(es): $\quad$ Paixão, Maria Paula
}

Publicado por: Imprensa da Universidade de Coimbra

URL

persistente: URI:http://hdl.handle.net/10316.2/31235

DOI: $\quad$ DOI:http://dx.doi.org/10.14195/978-989-26-0228-8_5

Accessed : $\quad$ 26-Apr-2023 12:57:33

A navegação consulta e descarregamento dos títulos inseridos nas Bibliotecas Digitais UC Digitalis, UC Pombalina e UC Impactum, pressupõem a aceitação plena e sem reservas dos Termos e Condições de Uso destas Bibliotecas Digitais, disponíveis em https://digitalis.uc.pt/pt-pt/termos.

Conforme exposto nos referidos Termos e Condições de Uso, o descarregamento de títulos de acesso restrito requer uma licença válida de autorização devendo o utilizador aceder ao(s) documento(s) a partir de um endereço de IP da instituição detentora da supramencionada licença.

Ao utilizador é apenas permitido o descarregamento para uso pessoal, pelo que o emprego do(s) título(s) descarregado(s) para outro fim, designadamente comercial, carece de autorização do respetivo autor ou editor da obra.

Na medida em que todas as obras da UC Digitalis se encontram protegidas pelo Código do Direito de Autor e Direitos Conexos e demais legislação aplicável, toda a cópia, parcial ou total, deste documento, nos casos em que é legalmente admitida, deverá conter ou fazer-se acompanhar por este aviso.

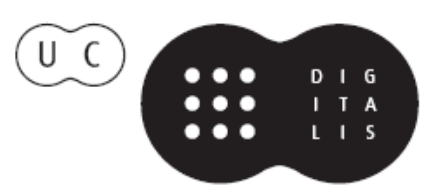




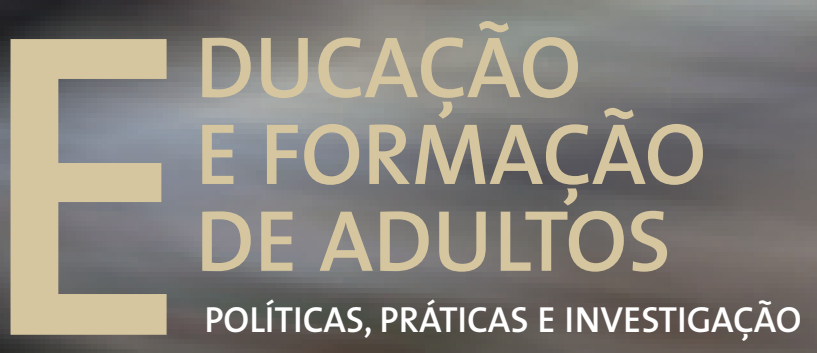

Luís Alcoforado • Joaquim Armando G. Ferreira António Gomes Ferreira • Margarida Pedroso de Lima Cristina Vieira • Albertina L. Oliveira • Sónia Mairos Ferreira 


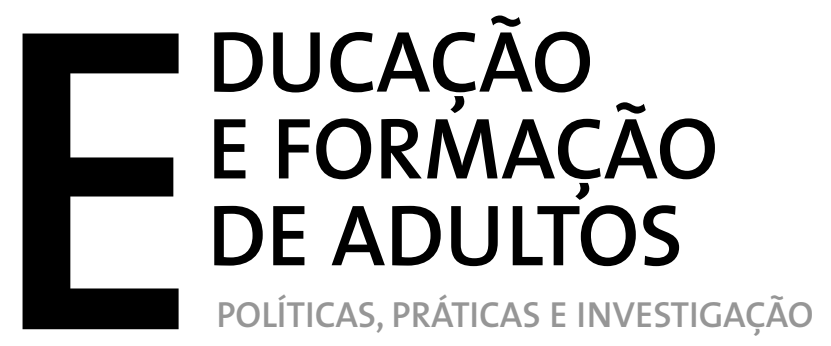

Luís Alcoforado • Joaquim Armando G. Ferreira António Gomes Ferreira - Margarida Pedroso de Lima Cristina Vieira • Albertina L. Oliveira • Sónia Mairos Ferreira 
EDIÇÃo

Imprensa da Universidade de Coimbra

URL: http://www.uc.pt/imprensa_uc

Vendas online: http://www.livrariadaimprensa.com

CONCEPÇÃO GRÁFICA

António Barros

Pré-Impressáo

SerSilito-Empresa Gráfica, Lda

EXECUÇÃo GRÁFICA

SerSilito-Empresa Gráfica, Lda

ISBN

978-989-26-0136-6

DePósito LEgaL

$340309 / 12$ 



\section{A ORIENTAÇÃo Na NEGociaçÃo das TRANSIÇÓES DE CARREIRA AO LONGO DA VIDA ADULTA}

Maria Paula Paixão

Universidade de Coimbra

\section{Introduçấo}

A carreira pode ser entendida como um conjunto organizado de padrôes de formação e de trabalho que constituem o trajecto de vida de um indivíduo. Neste âmbito podemo-nos perguntar, qual a relevância da abordagem da temática da orientação nas transiçóes de carreira ao longo da vida adulta. Numa primeira abordagem, podemos identificar quatro ordens de razóes: a) o trabalho assume um significado central na vida dos sujeitos, nomeadamente em todas as etapas do percurso pessoal ao longo da vida adulta, tendo igualmente um impacto relevante no desenvolvimento económico, social e cultural; b) o desenvolvimento humano pode ser compreendido através do conjunto das transiçôes em torno do trabalho efectuadas ao longo do ciclo de vida; c) a orientação é, na actualidade, identificada como uma área central de intervenção de âmbito educativo, psicológico e social, no seio das políticas de aprendizagem ao longo da vida e d) as sociedades mais industrializadas, nomeadamente no contexto Europeu, preocupam-se com a expansão e transformação profunda dos serviços de orientação que são capazes de providenciar aos seus cidadãos.

\section{O significado do trabalbo na vida dos sujeitos}

O trabalho envolve o sujeito numa relação complexa com o mundo, representando a interface mais consistente com os contextos sociais, económicos e políticos (Blustein, 2006)! Efectivamente, podemos identificar um conjunto de autores que têm reflectido sobre a forma como o encontro entre o trabalho e a satisfaçáo das necessidades humanas permite a construção do capital identitário (Blustein, 2008; Jahoda, 1983; Warr, 1987). Em primeiro lugar, o trabalho, enquanto construção psicossocial, permite satisfazer as seguintes necessidades, organizadoras do nosso sentido de identidade (Blustein, 2008):

a) Necessidades de sobrevivência e de poder. Podemos afirmar que estamos no domínio da satisfação das necessidades básicas, domínio no qual se podem facilmente reconhecer e integrar todos os cidadáos, em qualquer parte do mundo. Aliás, para muitos indivíduos são estas as únicas necessidades que pretendem e/ou conseguem ver satisfeitas através do envolvimento em actividades de trabalho. $\mathrm{O}$ envolvimento da satisfação da necessidade de poder confere, por parte dos membros de uma determinada sociedade, direito à participação em processos de tomada de decisão e está associado ao acesso aos mecanismos mínimos de regulação económica e social. Por exemplo, a entrada das mulheres no mercado trabalho contribuiu decisivamente para que a estas fosse reconhecido o direito de participar nas mais importantes escolhas e decisóes efectuadas em diversos níveis e domínios das diferentes esferas 
de participação social. Numa sociedade estratificada esse direito é objecto de várias restriçôes, não sendo o poder igualmente distribuído, no entanto as formas básicas de participação no tecido económico e social são, de uma forma geral, garantidas. O desemprego pode constituir uma barreira à satisfação das necessidades de sobrevivência e de poder, sobretudo se estiver dissociado de contextos diversificados e estáveis de suporte.

b) Necessidade de estabelecimento e envolvimento num conjunto amplo de redes sociais. O trabalho faculta o desenvolvimento de relaçóes significativas, permitindo o acesso a redes que possibilitam o desenvolvimento do capital social, através da ligação dos indivíduos ao contexto social e cultural mais abrangente. Para além deste importante aspecto, o trabalho funciona como um contexto privilegiado de estabelecimento de vínculos afectivos, cumprindo uma função inerente aos processos dinâmicos de desenvolvimento humano. A realização de actividades de trabalho possibilita, de igual modo, a prestação de cuidados a grupos-alvo específicos, nomeadamente crianças, idosos, pessoas com necessidades especiais, etc.

c) Necessidade de auto-determinação. Tendo como pano de fundo a teoria motivacional da auto-determinação de Deci \& Ryan (2002), que destaca a importância crucial dos contextos sociais na promoção da autonomia e do desenvolvimento optimal, o trabalho pode constituir o contexto ideal para a auto-expressão genuína de interesses, valores e competências promovendo, deste modo, o exercício da auto-determinação e da agência pessoal.

Algumas das teorias explicativas dos efeitos do desemprego na saúde mental apresentam importantes contribuiçóes para a compreensão do significado psicossocial do trabalho, pois sublinham o efeito negativo que a não satisfaçáo de algumas das suas funçóes acarreta na saúde mental dos cidadãos. Deste modo, a teoria da privação latente de Jahoda (1982) considera que o trabalho tem uma função manifesta (permitir a sobrevivência económica) e cinco funçóes latentes (estrutura temporal, contacto social, estatuto, actividade aplicada e propósito colectivo), de que os sujeitos desempregados são privados, o que pode provocar danos consideráveis no seu bem-estar físico e mental. Por outro lado, o modelo vitamínico de Warr (1987) acentua a ideia de que algumas das características do contexto de trabalho actuam como vitaminas, as quais (algumas apenas em doses moderadas) promovem a saúde mental (oportunidades de controlo, oportunidades para a utilização de competências, variedade, clareza contextual, segurança económica, segurança física, oportunidades para o contacto interpessoal, etc.), sendo que os indivíduos delas privadas podem ver comprometido o seu processo de crescimento pessoal na sociedade em que estáo inseridos.

Em suma, o trabalho está indissociavelmente ligado à construção e reconstrução da identidade psicossocial, desde logo porque as fantasias relativas ao trabalho expressam uma das mais precoces formas de antecipação da vida adulta (por exemplo, do ponto de vista das crianças, os adultos têm poder e capacidade de decisão porque trabalham). Além do mais, as respostas, constantemente reelaboradas à pergunta o que queres ser quando fores grande, em larga medida formatam o percurso formativo e vocacional das crianças e dos jovens, sobretudo nas sociedades mais desenvolvidas e envolvidas no processo de globalização. De facto, não podemos esquecer que a entrada na escola marca o início de uma grande narrativa de vida (organizada em torno de diversos episódios) que tem o trabalho como "tema unificador". Acresce, ainda, o facto de que a investigação e a intervenção no 
âmbito da reabilitação psicossocial dos doentes mentais têm abundantemente evidenciado a forte relação existente entre a recuperação da saúde mental e a transição para o mundo do trabalho (Leff, 2006). Finalmente, a interiorização do significado do trabalho no nosso percurso existencial faculta-nos o acesso a um vasto dicionário que nos possibilita a construção de narrativas várias e funcionais acerca da nossa relação com os outros e com o mundo, tendo em consideração que o utilizamos para regular o nosso comportamento pessoal e social e, simultaneamente, inferir acerca de atitudes, valores, estilos de vida, etc., dos outros com os quais interagimos.

\section{Desenvolvimento, trabalho e transiçóes}

A quase totalidade das perspectivas actuais sobre o comportamento e o desenvolvimento humano na sua relação com o trabalho e a aprendizagem ao longo da vida colocam-nos, de um ou outro modo, perante as problemáticas das mudanças ou transiçóes, da socialização ou do desempenho de papéis múltiplos em contextos diversificados e da própria construção identitária ao longo de trajectórias espácio-temporais não lineares (Guichard, 2010), ao sublinharem as características interactivas e emergentes dos sistemas complexos e ao clarificarem o acaso como a imprevisibilidade resultante da complexidade, acentuando a complementaridade das perspectivas convergentes (estabilidade) e emergentes (mudança) no aconselhamento de carreira (Amundson, 2006; Krumboltz, 2009; Pryor \& Bright, 2006).

Ao longo da idade adulta, e de acordo com Schlossberg (1981, 1997), as transiçôes são fundamentalmente de três tipos (esperadas, não antecipadas e transiçóes por não acontecimentos, isto é acontecimentos planeados e/ou antecipados, mas que não ocorreram), considerando estes autores que o processo de adaptação à transição (o qual depende, entre outros factores, das condiçóes específicas da própria situação de transição, das características do "self", dos tipos de apoio e das estratégias utilizadas) tem um impacto considerável no desenvolvimento psicossocial e na saúde física e mental dos cidadãos. Por sua vez, Fouad \& Bynner (2008) diferenciam claramente as transiçóes voluntárias das involuntárias, sublinhando que estas últimas (que apresentam um potencial de impacto negativo muito maior nos trajectos de desenvolvimento futuro) requerem apoios diversos e consistentes, que muitas vezes os sujeitos não conseguem obter, uma vez que colocam dificuldades e obstáculos difíceis de ultrapassar em diversos níveis. Efectivamente, de acordo com os autores anteriormente referidos, as transiçôes involuntárias são muitas vezes acompanhadas de obstáculos pessoais (ausência de tempo na preparação para a transição, falta de recursos emocionais, sociais e financeiros para a adaptação à transição). São, igualmente, acompanhadas de obstáculos na estrutura de oportunidades (preconceitos relativos ao género, idade, contextos económicos de estagnação ou recessão, imprevisibilidade das oportunidades), apresentando esses obstáculos, frequentemente, um carácter difuso, exercendo embora um impacto real e tangível. Finalmente, as transiçóes involuntárias são muitas vezes acompanhadas de obstáculos institucionais (desinvestimento em programas específicos de formação ou qualificação), os quais podem comprometer fortemente as dinâmicas de crescimento de indivíduos, grupos e organizaçóes. Fouad \& Bynner (2008) referem, ainda, que a capacidade dos sujeitos se adaptarem às transiçóes é moldada pelas políticas sociais e institucionais do contexto em que são efectuadas, nomeadamente sobre quem recai, em primeiro lugar, a responsabilidade da transição, isto é, o indivíduo (e as sua 
família e outros contextos proximais de apoio, pois neste caso os recursos governamentais são inexistentes, ou estão sob ameaça constante - perigo do “insourcing"), a sociedade (os termos inserção ou precariedade reflectem esta segunda tendência, ao admitirem a existência de contratos sociais e de haver a possibilidade do seu incumprimento ou quebra, mais ou menos temporária ou permanente), ou ambos.

Em qualquer dos casos, na perspectiva de diversos autores para além dos agora mencionados (Blustein et al., 2005; Motulsky, 2010), as transiçôes optimais estão normalmente associadas à existência de amplos recursos internos (competências de adaptabilidade ou o capital identitário necessário), assim como externos (sistemas de suporte). Pelo contrário, as transições fracassadas constituem um desafio sério para os trajectos pessoais e sociais de desenvolvimento, nomeadamente pelo facto de, na actualidade, estar plenamente documentada a sua associaçáo com estilos de vida marginalizados, situaçóes de vida desvantajosas e, mesmo, com a eclosão de quadros psicopatológicos (e.g. ver os estudos de Lucas et al, e de Paul e Moser, sobre o impacto negativo do desemprego, nomeadamente de longa duração, sobre a saúde mental dos sujeitos). De facto, Lucas et al. (2004) verificaram que o desemprego tem um impacto duradouro nos níveis basais de felicidade, mesmo após os sujeitos recuperarem o emprego. Na mesma linha de validação empírica, Paul \& Moser (2009), no estudo meta-analítico que efectuaram, e que envolveu 237 estudos transversais e 87 estudos longitudinais publicados durante os últimos 30 anos em diversos países, verificaram que o desemprego tem um impacto negativo na saúde mental, de magnitude média, detectado num espectro largo de indicadores: stresse, depressão, ansiedade, sintomatologia psicossomática, bem-estar subjectivo e auto-estima (a gravidade da sintomatologia clínica tende a aumentar entre $16 \%$ a $34 \%$, consoante a duração temporal do período de desemprego). Os dados avaliados relativamente a estes últimos 30 anos revelam, ainda, que este impacto negativo apresenta uma grande estabilidade ao longo das décadas envolvidas neste estudo. Como dados adicionais mais importantes que são salientados nesta investigação de referência, podemos referir que o género, o estatuto sócio-profissional e a duração do período de desemprego aparecem como moderadores muito significativos do efeito do desemprego na saúde mental: o efeito negativo é mais acentuado nos homens, nos trabalhadores com baixo estatuto sócio-profissional e em desempregados de longa duraçáo (acima dos 9 meses). Como outros moderadores significativos que são mencionados neste estudo temos o grau de desenvolvimento económico dos países, o seu carácter igualitário, o seu sistema de protecção social, os quais funcionam como "amortecedores" dos efeitos negativos do desemprego na saúde mental dos indivíduos.

\section{O papel da orientaçáo no âmbito das políticas de aprendizagem ao longo da vida}

Hopson (2009), numa linha idêntica à de diversos investigadores e profissionais que se têm debruçado sobre o futuro da carreira e o desenvolvimento de recursos pessoais, grupais e organizacionais no seio da "vertigem" de mudança e de transformação que caracterizam as sociedades contemporâneas mais avançadas (Arthur, Hall et al.), sublinha a ideia de que o padrão unidireccional de carreira deixou de ser dominante, partilhando o espaço com outros tipos de padróes de carreira que se tendem a reforçar e a ocupar posiçóes privilegiadas, tanto na óptica individual, como do ponto de vista mais societal, de que são exemplo a carreira em série, a carreira "estilo de vida" e, sobretudo, a carreira "portefólio". 
Estes últimos padróes tendem a ser caracterizados por uma enorme flexibilidade no que se refere aos tempos e aos espaços onde decorrem as vidas de trabalho (e não apenas o trabalho remunerado) dos indivíduos.

Neste contexto de insegurança e de incerteza a orientação pode, de acordo com Blustein (2008), promover o desenvolvimento, a saúde mental e a capacidade de contribuição para a comunidade, devendo os profissionais apoiar os sujeitos nas suas transiçôes voluntárias, bem como reforçar os seus recursos durante as transiçóes involuntárias, nomeadamente através da utilização de estratégias compreensivas englobando a aprendizagem e desenvolvimento de competências, o empoderamento, o desenvolvimento da consciência crítica e a "advocacia social".

A orientação tem sido identificada em documentos políticos da União Europeia e da OCDE como uma área central no que se refere à aprendizagem ao longo da vida e ao desenvolvimento económico e social das naçóes. O Boletim Informativo da OCDE (2002) afirma que o carácter sustentável das economias dos países depende, entre outros factores, da organização de condiçóes facilitadoras da transição para o mundo de trabalho, em que a intervenção vocacional tem um papel relevante, tendo esta mensagem saído reforçada no interior deste documento. Deste modo, para a OCDE e para a União Europeia (OCDE, 2005) este papel central é explicado, entre outros aspectos, pelo facto de possibilitar e incentivar o desenvolvimento do capital humano (Watts, 2005). De facto, como está bem patente em diversos documentos Europeus dedicados a esta temática (CEDEFOP, 2005; CIRIUS, 2009; ELGPN, 2010; McCarthy, 2009), é o indivíduo que dá coerência e sentido às aprendizagens efectuadas nos múltiplos contextos em que participa ao longo da vida, embora os sistemas nacionais ou internacionais de qualificaçáo possam certificar aprendizagens efectuadas e competências adquiridas e planear novas experiências que permitem a aquisição de novos conhecimentos e de novas competências. Adicionalmente, ao longo da vida adulta a orientação tem um papel importante na facilitação da transferência das aprendizagens e dos conhecimentos e competências adquiridos em diferentes contextos de vida, afirmando Guichard (2010) que as actividades de orientação estabelecem uma ligação pessoalmente significativa e socialmente útil entre os objectivos pessoais e as actividades económicas dos contextos em que os sujeitos estão inseridos.

Estes documentos Europeus tendem, igualmente, a enfatizar de uma forma bem clara e inequívoca que a competitividade económica e o bem-estar social, bem como a eficácia e a eficiência da educação, formação e do mercado de trabalho estão dependentes da qualidade das decisóes e das transiçóes efectuadas pelos cidadãos, devendo os serviços de orientação não apenas ser universalmente disponibilizados, como ser expandidos e consolidados seguindo padróes de qualidade solidamente validados.

\section{Transformaçáo e expansáo dos serviços de orientaçấo no contexto Europeu}

Já em 2003, tal como foi referido no início deste texto, J. Guichard afirmava que no actual contexto Europeu (e no contexto das sociedades mais industrializadas) as actividades de orientação podem ser organizadas e estruturadas de forma a responder às principais questóes levantadas pelos contextos, sendo estas diversamente valorizadas pelas diferentes forças activas actuando nesses contextos. Deste modo, os serviços de orientação podem estar estruturados de forma a responder às seguintes preocupaçóes dos diferentes agentes sociais: 
construção de uma visão mais realista em torno de mercado de trabalho (e.g. preocupação saliente dos empregadores, políticos, isto é, dos grupos mais responsáveis pelo ajustamento entre as dinâmicas da oferta e da procura), redução das desigualdades sociais e das medidas

fomentando a discriminação (e.g. preocupação de diversos agentes sociais, nomeadamente com responsabilidades educativas e no âmbito da reinserção social e profissional), formação da cidadania (e.g. preocupaçáo dos políticos, educadores e de outros agentes educativos e sociais actuando fundamentalmente ao nível da formação e da qualificação) e, finalmente, promoção do desenvolvimento integral dos sujeitos (e.g. preocupação dos sujeitos e respectivas famílias, e que, na realidade, abrange todos os cidadáos).

Seguindo um modelo conceptual e pragmático muito semelhante, Watts (2005), propóe três grandes tipos de objectivos para a orientaçáo: a) objectivos de aprendizagem e de desenvolvimento (promoção da aprendizagem e do desenvolvimento ao longo da vida a partir do fortalecimento das competências vocacionais); b) objectivos relativos ao mercado de trabalho (afinamento progressivo das dinâmicas promotoras do ajustamento entre a oferta e a procura); c) objectivos de igualdade social (relativos ao apoio à igualdade de oportunidades e à promoção da inclusão social).

Não é, portanto, de estranhar, a necessidade enfatizada em diversos documentos Europeus de transformar e expandir os serviços de orientaçáo vocacional no âmbito do modelo de aprendizagem ao longo da vida. A União Europeia e a OCDE, num documento elaborado tendo fundamentalmente em vista esclarecer os decisores acerca dos diversos eixos que devem enquadrar a tomada de decisão acerca das questóes de orientação (2005), definem a orientaçáo vocacional como um conjunto de "Serviços e actividades que pretendem apoiar as pessoas, de qualquer idade e em qualquer ponto ao longo do seu ciclo de vida, nas escolhas escolares, formativas e profissionais e na gestão das suas carreiras. Esses serviços podem funcionar em escolas, universidades e escolas superiores, em instituiçóes de formação, em centros públicos de emprego, no local de trabalho, no sector do voluntariado ou comunitário e no sector privado. As actividades podem realizar-se numa base individual ou em grupo, podem ser desenvolvidas numa interacção próxima (face-a-face) ou à distância (onde se incluem as linhas de ajuda e os serviços web). Compreendem a produção e difusão de informação sobre a carreira (recorrendo a documentos impressos, às TIC ou a outros métodos), instrumentos de avaliação e de auto-avaliação, entrevistas de aconselhamento, programas de educação/orientação vocacional (para ajudar as pessoas a desenvolver o conhecimento acerca de si próprias, o conhecimento acerca das oportunidades e as competências de gestão da carreira), programas de experiência e avaliação (para experimentar alternativas antes da escolha), programas de procura activa de emprego e serviços de apoio à transição" (p.14).

A orientação definida deste modo integra, pois, o conjunto de actividades que permitem aos sujeitos, ao longo do seu trajecto de vida, identificar as suas características vocacionais nucleares (competências, interesses, valores, etc.), ajudando-os a tomarem decisóes educativas e ocupacionais e a gerirem o seu percurso ou o seu trajecto de vida, articulando de uma forma harmoniosa e/ou identitariamente coerente as tarefas a realizarem nos seus principais contextos de inserção comportamental. Enquanto ferramenta de ajuda ao processo de construçáo psicossocial dos cidadãos compreende 4 eixos de acção, a saber: a) aquisição de competências de gestão da carreira por parte dos indivíduos - numa sociedade com múltiplas e rápidas mudanças é indispensável a construção de portefólios ou de identidades de carreira bastante flexíveis (Kuijpers et al., 2006); b) filosofia de acção desenvolvimen- 
tista e promocional, mais intensiva em momentos específicos de transição (desemprego, transiçốes no âmbito do contexto de trabalho ou da passagem à reforma, por exemplo) e particularmente direccionada para sujeitos enfrentando dificuldades ou barreiras específicas - é importante o recurso a metodologias diversificadas de intervenção, nomeadamente as TIC, pois estas garantem o acesso universal à informação e ao conhecimento disponível e utilizável; de igual modo, o reconhecimento, a validação e a certificaçáo de competências adquiridas em contextos nucleares de vida fomenta a igualdade de oportunidades dos cidadáos aos dispositivos formativos e de qualificação ${ }^{1}$; c) preocupação com a garantia de qualidade dos serviços prestados, propondo processos de avaliação de resultados tangíveis (mudanças efectivamente verificadas em contextos de trabalho, aprendizagem ou formação) ou mobilizáveis (mudanças nas atitudes e motivaçôes), a curto, médio ou a longo prazo, nos planos individual, económico e social, com recurso a metodologias variadas e com graus diversos de complexidade e, d) preocupação com a comunicação, cooperação e/ou a coordenaçáo das actividades, tarefas e propostas de intervenção por parte de todos os intervenientes, evitando a fragmentação dos serviços e fomentando o estabelecimento de parcerias entre os diferentes contextos de ensino e de aprendizagem (ELGPN, 2010).

Assim, e tomando como exemplo o caso dos adultos desempregados, a meta relativa ao aumento do grau de empregabilidade por parte destes sujeitos deve ter em consideração as suas necessidades diferenciadas, permitindo o seu acesso a serviços de orientação diversificados e disponibilizados numa rede hierarquizada de ofertas de intervenção, de acordo com o seu grau de "intensidade", desde a prestação de alguma informação, passando pelos tratamentos breves (algumas entrevistas a actividades de âmbito psicoeducativo) até aos mais intensivos e individualizados (aconselhamento pessoal e de carreira).

Concluindo, numa sociedade moderna e igualitária a orientação deve ter em consideração as características dos contextos de vida dos cidadãos, desde os mais proximais (microcontextos), até aos mais distais (macrocontextos), bem como as suas influências recíprocas e bidireccionais, uma óptica de optimização e de compensação dos processos psicossociais de desenvolvimento (Vondracek, Lerner \& Schulenberg, 1986). Com efeito o trabalho é hoje, mais do que nunca, objecto privilegiado de estudo das ciências sociais e humanas, pois constitui um contexto nuclear de desenvolvimento, no âmbito do qual se organizam os mais importantes marcadores psicológicos, potencialmente originadores de sofrimento ou de bem-estar e possibilitando, sobretudo, a estagnação e a rigidez ou, pelo contrário, fomentando a plasticidade e a resiliência.

\section{Referências Bibliográficas}

Amundson, N. (2006). Walking the yellow brick road. Journal of Employment Counseling, 43, 31-38.

Arthur, M. B. (1994). The boundaryless career: A new perspective for organizational inquiry. Journal of Organizational Behavior, 15, 295-306.

1 Exemplo paradigmático desta filosofia desenvolvimentista e promocional de acção é o programa Canadiano “Blueprint for Life/Work Designs" (Redekopp, Haché \& Jarvis, 2006), o qual propõe a aquisição de um conjunto integrado de competências, que vão desde a gestão pessoal (construir e manter uma representação de si positiva e adquirir a capacidade para estabelecer interacçóes eficazes), à competência para explorar de forma sistemática os contextos de aprendizagem e de trabalho, até à possibilidade genérica de construção da vida/trabalho, através do envolvimento activo em papéis mutáveis e flexíveis de vida e de trabalho, com um notável grau de equilíbrio. 
Blustein, D (2006). The Psychology of working: A new perspective for career development, counselling and public policy. Mahwah, NJ: Erlbaum.

Blustein, D. (2008). The role of work in psychological health and well-being. American Psychologist, 63 (4), 228-240.

Blustein, D. L., McWhirter, E. H., \& Perry, J. C. (2005). An emancipatory communitarian approach to vocational development theory, research and practice. The Counseling Psychologist, 33, 141-179.

Blustein, D., Kenna, A., Gill, N. \& DeVoy, J. (2008). The psychology of working: A new framework for counselling practice and public policy. The Career Development Quarterly, 56 (4), 294-308.

CEDEFOP (2005). Improving lifelong guidance policies and systems. Using common European reference tools. Luxembourg: Office for Official Publications of the European Communities.

CIRIUS (2009). Guidance of adults in the EU. A catalogue of European co-operation projects of guidance on adults. Copenhagen: Education an Culture DG Lifelong Learning Programme.

Deci, E. \& Ryan, R. (2002). Handbook of self determination research. Rochester: The University of Rochester Press.

ELGPN (2010). Lifelong Guidance Policies: Work in progress. A report on the work of the European Lifelong Guidance Policy Network 2008-10. University of Jyväskylä, Finland: Finnish Institute for Educational Research (FIER).

Fouad, N. \& Bynner, J. (2008). Work transitions. American Psychologist, 63(4), 241-251.

Guichard, J. (2010). L'activité comme support théorique et pratique pour le conseil en orientation. Pratiques Psychologiques, 16, 85-98.

Guichard, J. (2003). Career counseling for human development: an international perspective. Career Development Quarterly, 51, 306-321.

Hall, D. T., \& Moss, J. E. (1998). The new protean career contract: Helping organizations and employees adapt. Organizational Dynamics, 26 (3), 22-37.

Hopson, B. (2009). From vocational guidance to portfolio careers: A critical reflection. International Centre for Guidance Studies (iCeGS): University of Derby, UK.

Jahoda, M. (1982). Employment and unemployment: A social-psychological analysis. Cambridge, England: Cambridge University Press.

Krumboltz, J. (2009). The happenstance learning theory. Journal of Career Assessment, 17, 135-154.

Kuijpers, M., Schyns, B. \& Scheerens, J. (2006). Career competencies for career success. The Career Development Quarterly, 55 (2), 168-178.

Leff, J. (2006). Social Inclusion of People with Mental Illness. Cambridge: Cambridge University Press.

Lucas, R. E., Clark, A. E., Georgellis, Y., \& Diener, E. (2004). Unemployment alters the set-point for life satisfaction. Psychological Science, 15, 8-13.

McCarthy, J. (2009). Desenvolvimento de políticas de orientação, formação e emprego na União Européia. Revista Brasileira de Orientação Profissional, 10 (1), 103-109.

Motulsky, S.L. (2010). Relational processes in career transition: Extending theory, research and practice. The Counseling Psychologist, 38 (8), 1078-1114.

OECD (August 2002). An OECD Review of Policies for Information, Guidance and Counselling Services. Brussels: European Commission and the OECD.

OECD (2005). Orientação Escolar e Profissional. Guia para Decisores. Lisboa: Direcção Geral de Inovação e Desenvolvimento Curricular e Instituto de Orientação Profissional.

Paul, K, I. \& Moser, K. (2009). Unemployment impairs mental health: Meta-analyses. Journal of Vocational Behavior, 74, 264-282.

Pryor, R. \& Bright, J. (2006). Counseling chaos: Techniques for practitioners. Journal of Employment Counseling, 43, 2-16.

Redekopp, D., Haché, L. \& Jarvis, P. (2006). Blueprint for Life/Work Designs. New-Brunswick, Canada: National Life/Work Center.

Schlossberg, N.K. (1981). A model for analyzing human adaptation to transition. Counseling Psychologist, 9 (2), 2-18.

Schlossberg, N.K. (1997). A model of worklife transitions. In R. Feller and G. Walz (Eds.), Career Transitions in Turbulent Times. Greensboro: Eric Counseling \& Student Services Clearinghouse.

Vondracek, F. W., Lerner, R.M. \& Shulenberg, J.E. (1986). Career development: a life-span developmental approach. (pp. 35-66; 155-174). Hillsdale, NJ: Erlbaum Associates.

Warr, P. (1987). Work, Unemployment, and Mental Health. Clarendon Press: Oxford.

Watts, A. (2005). Career guidance policy: An international review. The Career Development Quarterly, 54 (1), 66-76. 

Série Documentos

Imprensa da Universidade de Coimbra

Coimbra University Press

2011

- U

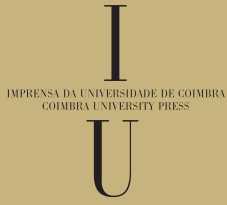

